\title{
The Effects of Repeated Exposure to Garlic- Flavored Milk on the Nursling's Behavior
}

\author{
JULIE A. MENNELLA AND GARY K. BEAUCHAMP
}

Monell Chemical Senses Center, Philadelphia, Pennsylvania 19104-3308

\begin{abstract}
The present study investigated whether prior consumption of garlic by nursing mothers modifies their infants' behaviors during breast-feeding when the mothers again consume garlic. Three groups of mother-infant dyads were studied. The groups differed in the type (placebo or garlic) or the timing (d 5-7 or 8-10) of capsule ingestion by the mothers and, consequently, in the amount and recency of exposure their infants had to garlic-flavored milk during an 11-d experimental period. Each motherinfant pair was observed during two 4-h test sessions. The first session occurred at the beginning of the experimental period, when the mothers ingested placebo capsules (d 4); the second occurred at the end of the experimental period, when they ingested garlic capsules (d 11). During test sessions, the infants fed on demand and were weighed before and after each breast-feeding to determine the amount of milk ingested, and their behaviors during breastfeeding were monitored by videotape. The results demonstrated an effect of prior experience with garlic in mother's milk. The infants who had no exposure to garlic volatiles in their mothers' milk during the experimental period spent significantly more time breast-feeding after their mothers ingested garlic capsules compared with those infants whose mothers repeatedly consumed garlic during the experimental period. Moreover, the former group of infants spent significantly more time attached to their mothers' breasts during the 4-h test session in which their mothers ingested the garlic compared with the session in which she ingested the placebo. In contrast, the infants of mothers who consumed garlic capsules during the experimental period showed no response to the mothers' ingestion of garlic at the end of the experimental period (i.e. the time spent breast-feeding was equivalent to that observed during the session in which their mothers ingested the placebo capsules). Neither the number of times the infants fed nor the amount of milk they consumed was significantly affected by maternal garlic ingestion. (Pediatr Res 34: 805-808, 1993)
\end{abstract}

\section{Abbreviations}

ANOVA, analysis of variance

Human milk is not just a complex mixture of substances that best meets the nutritional requirements of the infant. It is a food that varies in flavor because selected volatiles from the mother's diet are transmitted to her milk $(1,2)$. Like the milk of other

Received May 12, 1993; accepted August 4, 1993.

Correspondence and reprint requests: Julie A. Mennella, Ph.D., Monell Chemical Senses Center, 3500 Market St., Philadelphia, PA 19104-3308.

Supported in part by a National Research Service Award (HD07375) and by a grant (DC00882) from the National Institutes of Health. J.A.M. is a Morley R. Kare Fellow. mammals (3), the flavor of human milk is altered when lactating women eat sulfur-containing foods such as garlic (1). When human milk is flavored with garlic, the infants breast-feed longer and suck more overall than they do when this flavor is absent, at least under conditions in which the mothers have been ingesting bland diets for several days (1).

Several hypotheses can be suggested to account for this increased responsiveness during breast-feeding after the infants' mothers consumed garlic. First, the infants may be attracted to or stimulated by garlic volatiles. Although there is no evidence that the flavor of garlic is inherently attractive to human infants in the same way that sweet sugars are (4), a variety of carnivore and omnivore species are attracted to semiochemicals that contain sulfur, and cats and dogs eat more food when it is flavored with garlic (5). Second, the infants may be responding to a familiar, and thus pleasant, flavor previously experienced in their mother's milk (1), amniotic fluid (6), or both. Third, the infants may be responding to nonspecific changes in the flavor of the mother's milk. Because the mothers in our previous study (1) ate a diet low in sulfur-containing foods during the experimental period, their milk may have been bland. Perhaps the change to a garlic-flavored milk acted as a stimulant for suckling, a phenomenon similar to that observed in adults when a change in the type and flavor of available foods stimulates intake (7).

In the present study, we began investigating these hypotheses by manipulating the nursing mother's diet and, consequently, her infant's experience with garlic-flavored milk, and then evaluating the infant's response to garlic-flavored milk during a subsequent feeding.

\section{MATERIALS AND METHODS}

Subjects. Thirty healthy, nonsmoking women whose infants were exclusively breast-feeding were recruited from local newspapers and from the Women, Infants and Children Program at North, Inc. in Philadelphia. Six additional mothers began testing but were disqualified because they did not comply with the testing procedures. All study procedures were approved by the Committee on Studies Involving Human Beings at the University of Pennsylvania, and informed consent was obtained from each woman before entry into the study.

Three groups, each consisting of 10 mother-infant pairs, were formed. The characteristics of the subjects in each group are listed in Table 1 . There was no significant difference between the groups in the ages of the mothers $[F(2,27)=1.68, p=0.21]$ or infants $[F(2,27)=0.09, p=0.92]$. Each group consisted of five female and five male infants.

To assess how often each mother consumed sulfur-containing foods during pregnancy and lactation, a food frequency questionnaire listing sulfurous foods (e.g. garlic, onions, and broccoli) was completed by each subject (8). This revealed that all mothers ate garlic and other sulfur-containing foods occasionally. None of the mothers had consumed any type of garlic capsule before entry into the study.

Procedure. Each mother-infant dyad participated in the study 


\begin{tabular}{lccc}
\hline & $\begin{array}{c}\text { Group 1 } \\
\text { (No recent } \\
\text { exposure to } \\
\text { garlic) }\end{array}$ & $\begin{array}{c}\text { Group 2 } \\
\text { (Garlic exposure } \\
\text { on d 5-7) }\end{array}$ & $\begin{array}{c}\text { Group 3 } \\
\text { (Garlic exposure } \\
\text { on d 8-10) }\end{array}$ \\
\hline Mother's age (y) & & & $30.8 \pm 2.0$ \\
Mean \pm SD & $31.7 \pm 1.3$ & $28.0 \pm 1.3$ & 32.0 \\
Median & 33.0 & 27.5 & $124.6 \pm 17.1$ \\
Infant's age (d) & $120.3 \pm 15.2$ & $128.1 \pm 8.5$ & 117 \\
Mean \pm SD & 124 & 134 & $5 / 5$ \\
Median & $5 / 5$ & $5 / 5$ & 10 \\
Sex of infant (female/male) & 10 & 10 & 10 \\
$n$
\end{tabular}

for $11 \mathrm{~d}$ during which each mother was instructed to eat a "bland" diet low in sulfur-containing foods. The mothers were given a list of foods (e.g. garlic, onion, and asparagus) and spices (e.g. garlic powder, onion powder) to avoid. To encourage compliance, they were asked to record (in terms of household measures) all foods and beverages consumed during this period [see Mennella and Beaucahmp $(1,2)$ for further description of methods].

After maintaining a bland diet for $3 \mathrm{~d}$, each mother and infant came to the Monell Center on the morning of $d 4$. At the beginning of the test session, each mother ingested placebo capsules. During the next $4 \mathrm{~h}$, her infant breast-fed at the frequency customary for each mother-infant dyad (9). Each mother chose which breast the baby suckled from first and whether the second breast was offered. Milk intake was assessed by weighing the infants immediately before and after each feed (10), and the infants' behaviors during breast-feeding were monitored by videotape $(1,2)$.

At the end of this first test session, mothers were given a packet of either placebo capsules containing lactose or capsules containing $1.5 \mathrm{~g}$ of garlic extract (General Nutrition Center, Pittsburgh PA) and instructions regarding when to take the capsules. The mother was not told which type of capsule she was given. As illustrated in Figure 1, although the testing procedures on $\mathrm{d} 4$ and 11 were identical for all three groups, the groups differed in the type (placebo or garlic) or the timing (d 5-7 or d 8-10) of capsule ingestion by the mothers and, consequently, in the amount and recency of exposure their infants had to garlicflavored milk at they time of the second testing session on $\mathrm{d} 11$. That is, the mothers in group 1 ingested placebo capsules on $d$ $7-10$, and their infants therefore, were not exposed (or, at the most, minimally exposed) to garlic-flavored milk during the 10 $\mathrm{d}$ preceding test $\mathrm{d} 11$. In contrast, the mothers in group 3 ingested garlic capsules during $d 8-10$, and their infants therefore had been exposed to the garlic during the $3 \mathrm{~d}$ immediately preceding test d 11. Group 2 infants also experienced garlic-flavored milk,

\section{Experimental Design}

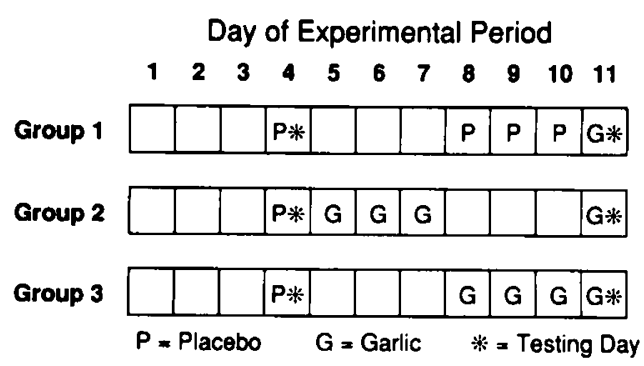

Fig. 1. The design of the experimental protocol for the three groups of subjects. The subjects in each group consumed a low-sulfur diet during all $11 \mathrm{~d}$ of the experimental period. $P$ indicates the days that the mothers consumed the placebo capsules; $G$ indicates the days that the mothers consumed the garlic capsules; ${ }^{*}$ indicates the test days in which the infant's feeding behavior was monitored at the Monell Center. but because they were exposed during d 5-7 of the experimental period, $3 \mathrm{~d}$ had elapsed between the last day their mothers had ingested any substantial amount of garlic and the test day. Pilot testing in our laboratory revealed that this is sufficient time for the milk to be free of detectable garlic odors.

On the final experimental day (d 11), the mothers and infants returned to the Monell Center. The testing procedures of $d 4$ were repeated, but instead of ingesting placebo capsules, each mother ingested capsules containing $1.5 \mathrm{~g}$ of garlic extract. The time of day that the mothers ingested the capsules on test $\mathrm{d} 4$ and 11 was the same time she ingested the capsules at home.

During replays of the videotapes, observers who were blind to the conditions of the feeding recorded the length of time the infants spent attached to the nipple during each breast-feeding. The method of Drewett et al. (11) was used to determine the number of feedings per testing session. A feeding was defined as the period of attachment to the breast such that if the interval between detaching from one breast and reattaching to the other was less than $5 \mathrm{~min}$, then these adjacent breast-feedings were treated as components of a single feeding.

Statistical analyses. For each infant, we determined the total milk intake, time attached to the nipple, and number of feedings that occurred during the $4 \mathrm{~h}$ after the mother consumed the placebo capsules (d 4) and after she consumed the garlic capsules (d 11). These data were analyzed in separate $2 \times 3$ ANOVA (SPSS/PC+) with test session (placebo or garlic) as a repeated factor and condition (group 1, 2, or 3) as a grouping factor. After significant interaction effects, one-way ANOVA with post hoc Tukey tests were performed to assess group differences, and paired $t$ tests, using the Bonferroni procedure, were performed to assess differences within each group. All summary statistics are expressed as mean \pm SEM.

\section{RESULTS}

The total time the infants of each group were attached to their mother's nipples during the test sessions in which their mothers consumed placebo capsules (d 4) and garlic capsules (d 11) is shown in Table 2. The ANOVA revealed a significant interaction between the amount of exposure the infants had to garlic-flavored milk during the experimental period (condition) and the type of capsules the mothers ingested during the test session [condition $\times$ test session: $F(2,27)=6.80, p=0.004$ ], and a significant main effect for condition $[F(2,27)=3.80, p=0.04]$ but not for test session $[F(2,27)=0.01, p=0.91]$.

Probing the significant interaction revealed that there was no significant difference between the groups in the length of the feedings occurring when mothers consumed placebo capsules $[F(2,27)=1.42, p=0.26]$, but there was a significant difference during the test session when the mothers consumed the garlic capsules $[F(2,27)=5.91, p=0.007]$. The infants whose mothers maintained a bland diet and ingested the placebo capsules during d 7-10 (group 1) spent more time breast-feeding during the test session in which their mothers consumed garlic than did group $2(p<0.05)$ and group 3 infants $(p<0.05$; see Table 2$)$. 
Table 2. Effect of garlic exposure on infants' feeding behaviors*

\begin{tabular}{|c|c|c|c|}
\hline & $\begin{array}{c}\text { Group 1 } \\
\text { (No recent } \\
\text { exposure to garlic) }\end{array}$ & $\begin{array}{c}\text { Group } 2 \\
\text { (Garlic exposure } \\
\text { on d 5-7) }\end{array}$ & $\begin{array}{c}\text { Group } 3 \\
\text { (Garlic exposure } \\
\text { on d } 8-10 \text { ) } \\
\end{array}$ \\
\hline \multicolumn{4}{|c|}{ Total time attached to nipple (min) } \\
\hline Placebo test session & $37.6 \pm 4.4$ & $28.0 \pm 2.7$ & $34.1 \pm 4.9$ \\
\hline Garlic test session & $47.9 \pm 5.8 \dagger$ & $24.6 \pm 3.7 \ddagger$ & $27.8 \pm 5.8 \ddagger$ \\
\hline \multicolumn{4}{|l|}{ Total milk intake (mL) } \\
\hline Placebo test session & $193.4 \pm 19.2$ & $243.4 \pm 22.5$ & $204.7 \pm 14.2$ \\
\hline Garlic test session & $200.9 \pm 16.2$ & $215.9 \pm 23.1$ & $200.2 \pm 18.3$ \\
\hline \multicolumn{4}{|l|}{ Total number of feedings } \\
\hline Placebo test session & $3.1 \pm 0.3$ & $3.2 \pm 0.2$ & $2.4 \pm 0.3$ \\
\hline Garlic test session & $3.3 \pm 0.3$ & $2.9 \pm 0.2$ & $2.5 \pm 0.3$ \\
\hline$n$ & 10 & 10 & 10 \\
\hline
\end{tabular}

* The total time attached to the nipple, the amount of milk consumed, and the number of feedings are shown for each of two 4-h test sessions on $\mathrm{d} 4$ and 11 of the experimental period. During the session on $\mathrm{d} 4$, the mothers consumed placebo capsules, whereas on d 11 they consumed garlic capsules. Group 1 infants had no exposure to the garlic capsules during test $d 1$ through 10 ; group 2 infants had exposure to the garlic capsules on d 5-7 of the experimental period; and group 3 infants had exposure to the garlic capsules during $\mathrm{d} 8-10$.

$+p<0.01$ vs same group in the placebo test session.

$\ddagger p<0.05$ vs group 1 in the same test session.

Moreover, group 1 infants spent significantly more time attached to their mother's breasts during the 4-h test session (d 11) in which their mother ingested the garlic ( $47.9 \pm 5.8 \mathrm{~min})$ compared with the test session (d 4) in which she ingested the placebo capsules [37.6 $\pm 4.4 \mathrm{~min}$; paired $t(9 d f)=-3.33, p=0.009$; see Table 2]. As illustrated in Figure 2, the group 1 infants breastfed, on average, $30.8 \%$ longer when their mother's milk was flavored with garlic. Although there was a tendency for the infants who were exposed to garlic during the experimental period (groups 2 and 3 ) to spend less time breast-feeding when their mothers again consumed garlic (test $d 11$ ) compared with when their mothers consumed the placebo capsules (test d 4), this was not significant for either group 2 [paired $t(9 d f)=0.91, p=0.39$ ] or group 3 [paired $t(9 d f)=1.86, p=0.10$; see Table 2].

The amount of milk consumed by the infant [condition $\times$ test session: $F(2,27)=1.34, p=0.28$; condition: $F(2,27)=0.99, p=$ 0.39 ; test session: $F(2,27)=0.84, p=0.37$ ] and the number of times the infants fed during the testing sessions [condition $\times$ test session: $F(2,27)=0.84, p=0.44$; condition: $F(2,27)=2.92, p=$

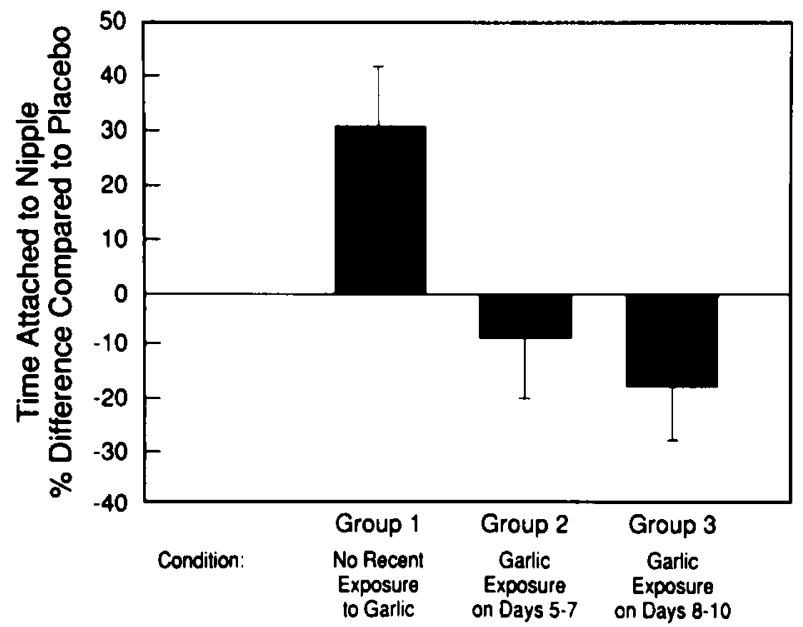

Fig. 2. Percent difference in the amount of time the infants were attached to the nipple during the 4-h test session in which the mother consumed the garlic capsules (d 11) compared with the time attached when she consumed the placebo capsules (d 4). Group 1 infants had no exposure to the garlic capsules during test $d 1$ through 10 . Group 2 infants had exposure to the garlic capsules on d 5-7 of the experimental period and Group 3 infants had exposure to the garlic capsules during $d$ 8-10. Each infant's behaviors were monitored on two separate days, on d 4 when their mother ingested placebo capsules and on d 11 when she ingested garlic capsules.
0.07 ; test session: $F(2,27)=0.00, p=1.00]$ were not affected by the amount of exposure the infant had to garlic-flavored milk during the experimental period, the type of capsules ingested by the mother during the test session, or their interaction.

Because garlic ingestion by the lactating woman is said to be associated with "colic" in the breast-feeding infant (12), we asked each mother at the end of the study whether she noticed a change in her infant's behavior during the days that she took the capsules at home. Recall that none of the mothers were told what type of capsule they were given. Of the 20 women who ingested the garlic capsules at home (groups 2 and 3), all believed they had ingested garlic capsules, but only four reported that their infants were colicky during these $3 \mathrm{~d}$; that is, they were fussier, cried more, or "had more gas." Interestingly, four of the 10 women who had ingested placebo capsules during these $3 \mathrm{~d}$ (group 1) believed they had ingested garlic capsules; each of these women also reported that their infants were colicky.

\section{DISCUSSION}

Prior and repeated consumption of garlic by nursing mothers modified their infants' behaviors during breast-feeding when the mothers again consumed garlic. That is, the infants of mothers who had repeatedly consumed the garlic capsules during the experimental period (groups 2 and 3 ) breast-fed for similar periods of time during the 4-h test session in which their mothers consumed garlic (d 11) compared with the session in which their mothers ingested the placebo (d 4). In contrast, the infants who had no or minimal exposure to garlic volatiles in their mother's milk during the experimental period (group 1) spent more time breast-feeding when their mothers ingested garlic than when their mothers ingested the placebo, thus corroborating our previous findings (1).

Perhaps the garlic flavor became monotonous to those infants who were repeatedly exposed to it in mother's milk (groups 2 and 3). Over the short term, children (13) and adults (7) report that the palatability of a food, and the amount of it consumed, declines after repeated consumption of that food, whereas less recently consumed foods are considered more palatable and stimulate food intake. Moreover, the garlic-flavored milk may have aroused the infants who were exposed to a diet of mother's milk relatively low in flavor, garlic-like compounds, or both (group 1). When aroused, mammalian infants will suck more (14) and exhibit a variety of other oral behaviors $(15,16)$. This enhanced suckling time did not result in an increase in milk intake, however. The absence of an effect on the infant's milk intake may reflect milk availability, infant capacity, or both. Nonetheless, these findings suggests that the sensory attributes of 
mother's milk may contribute to the patterning and duration of suckling at the breast.

What other factors could account for the effects of prior exposure to garlic on the infants' suckling behavior? First, it is possible that the infants in group 3, who were repeatedly exposed to garlic during the $3 \mathrm{~d}$ immediately preceding testing, were less able to detect the garlic in their mother's milk because they had adapted to the odor. Continued or repeated exposure to an odor results in a relatively rapid suppression of the perceived intensity of that odor presumably because the olfactory receptors have fatigued $(17,18)$.

Although the phenomenon of sensory adaptation can explain the differences observed between group 1 and group 3 infants, it cannot account for the response of the infants in group 2, who were exposed to the garlic for $3 \mathrm{~d}$ but had $3 \mathrm{~d}$ of no exposure interpolated before the test $\mathrm{d} 11$. In unpublished studies, we found that adult panelists could not detect a garlic or stronger odor in the milk within $72 \mathrm{~h}$ after the mothers last consumed the third dose of the garlic capsules. Because recovery from adaptation is relatively fast (19), it seems unlikely that the infants in group 2 were adapted to the garlic odor. One caveat to this argument needs to be noted, however. Anecdotal reports claim that prolonged exposure to an odor, such as one's body odor or the odor of one's home and work place, often results in what appears to be a relatively long-term adaptation-like phenomenon (20). We are aware of no scientific research in this area, so the possibility that the infants in group 2 could not detect the garlic odors in their mother's milk remains speculative.

Second, the infants in both groups 2 and 3 could have habituated to the odor of garlic. Habituation, unlike adaptation, does not involve a decrease in actual sensitivity to the stimulus but is the result of the individual getting used to or ignoring a stimulus and thus is a centrally mediated process (21). Although the habituation hypothesis can explain the response of both groups of infants who were exposed to garlic, additional studies are required before this explanation can be accepted.

Although much research will be required to fully understand the effects of exposure to flavors in mother's milk on the infant's behavior, several points are clear. First, human milk is not a food of invariant flavors $(1,2)$. Rather, it provides the potential for a rich source of varying chemosensory experiences to the infant. Second, the prior flavor experiences of mothers, and consequently their infants, may modify the infants' responses to these flavors.

Based on a variety of animal model studies (22-27), the infant's prior exposure to flavors in mother's milk could actually increase the desirability of those flavors through familiarization or even an imprinting-like attachment. For example, all the mothers in our previous study (1) and the present study consumed some garlic during pregnancy and lactation, thereby possibly exposing their infants to the flavor of garlic. This exposure could have contributed to the apparent attraction of their infants to the garlic-flavored milk, at least under the conditions in which the mothers had been ingesting bland diets for several days. Unfamiliar foods, which are often not preferred by children, become preferred after repeated presentation and increased familiarity $(28,29)$.

Studies on other animals (30) also suggest that experience with a variety of flavors during breast-feeding, in contrast to the invariant flavor experience of formula-feeding, could increase the infants' willingness to accept a variety of flavors. Indeed, a recent study suggested that breast-fed infants consume more of a novel vegetable than do formula-fed infants (31).

The flavor world of the breast-fed infant potentially is much richer than previously thought. Besides garlic (1), findings from our laboratory reveal that a wide variety of flavors $(e . g$. alcohol (2) mint, and cheese) ingested by the lactating woman are transmitted to her milk. Whether exposure to these flavors in mother's milk affects the infant's later preferences, development of food habits, and willingness to accept new foods at weaning or thereafter remains an important research area that needs to be fully explored.

Acknowledgments. The authors thank Mary Beth Haas, RN, MSN, of the WIC program at North, Inc. for her help in recruiting subjects; Hillary Bogner, Carol Staley, Amy Gagliardi, and Tawana Bannerman for technical assistance; and Drs. Beverly Cowart and Barry Green for helpful comments on an earlier version of the manuscript.

\section{REFERENCES}

1. Mennella JA, Beauchamp GK 1991 Maternal diet alters the sensory qualities of human milk and the behavior of the nursling. Pediatrics 88:737-744

2. Mennella JA, Beauchamp GK 1991 The transfer of alcohol to human milk: effects on flavor and the infant's behavior. N Engl J Med 325:981-985

3. Bassette R, Fung DYC, Mantha VR 1986 Off-flavors in milk. Crit Rev Food Sci Nutr 24:1-52

4. Desor JA, Maller O, Greene LS 1977 Preference for sweet in humans: infants, children and adults. In: Weiffenbach JM (ed) Taste and Development: The Genesis of Sweet Preference, US Government Printing Office, Washington, DC, pp 161-172

5. Mason JR, Epple G, Nolte DL 1993 Semiochemicals and improvements in rodent control. In: Galef BG, Valsecchi P, Mainardi M (eds) Ontogeny and Social Transmission of Food Preferences in Mammals: Basic and Applied Research Harwood Academic Press, London (in press)

6. Hauser GJ, Chitayat D, Berns L, Braver D, Mulhauser B 1985 Peculiar odours in newborn and maternal pre-natal ingestion of spicy foods. Eur $J$ Pediatr 44:403

7. Rolls BJ, Rowe ES, Rolls ET 1982 How sensory properties of foods affect human feeding behavior. Physiol Behav 29:409-417

8. Mullen BJ, Krantzler NJ, Grivetti LE, Schultz HG, Meiselman HL 1984 Validity of a food frequency questionnaire for the determination of individ ual food intake. Am J Clin Nutr 39:136-142

9. Howie PW, Houston MJ, Cook A, Smart L, McArdle T, McNeilly AS 1981 How long should a breast feed last? Early Hum Dev 5:71-77

10. Butte NF, Wong WW, Patterson BW, Garza C, Klein PD 1988 Human-milk intake measure by administration of deuterium oxide to the mother: a comparison with the test-weighing technique. Am J Clin Nutr 47:815-821

11. Drewett RF, Woolridge MW, Jackson DA, Imong SM, Mangklabruks A, Wongsawasadii L 1989 Relationships between nursing patterns, supplementary food intake and breast-milk intake in a rural Thai population. Early Hum Dev 20:13-23

12. Snow LF, Johnson SM 1978 Folklore, food, female reproductive cycle. Ecol Food Nutr 7:41-49

13. Birch LL, Deysher M 1986 Caloric compensation and sensory specific satiety: evidence for self-regulation of food intake by young children. Appetite 7:323 331

14. Bridger WH 1962 Ethological concepts and human development. Recent Adv Biol Psychiatry 4:95-107

15. Korner AF, Chuck B, Dontchos S 1968 Organismic determinants of spontaneous oral behavior in neonates. Child Dev 39:1145-1157

16. Terry LM, Johanson IB 1987 Olfactory influences on the ingestive behavior of infant rats. Dev Psychobiol 20:313-332

17. Rovee CK 1972 Olfactory cross adaptation and facilitation in human neonates. J Exp Child Psychol 13:368-381

18. Todrank J, Wysocki CJ, Beauchamp GK 1991 The effects of adaptation on the perception of similar and dissimilar odors. Chem Senses 16:467-482

19. Steinmetz G, Pryor GT, Stone H 1970 Olfactory adaptation and recovery in man as measured by two psychophysical techniques. Perception and Psychophysics 8:327-330

20. Moncrieff RW 1951 The Chemical Senses. The University Press, London

21. Engen T 1982 The Perception of Odors. Academic Press, New York

22. Galef BG, Henderson PW 1972 Mother's milk: a determinant of the feeding preferences of weaning rat pups. J Comp Physiol Psychol 78:213-219

23. Galef BG, Sherry DF 1973 Mother's milk: a medium for transmission of cues reflecting the flavour of mother's diet. J Comp Physiol Psychol 83:374-378

24. Campbell RG 1976 A note on the use of feed flavour to stimulate the feed intake of weaner pigs. Anim Prod 23:417-419

25. Mainardi M, Poli M, Valesecchi P 1989 Ontogeny of dietary selection in weaning mice: effects of early experience and mother's milk. Biol Behay 14:185-194

26. Nolte DL, Provenza FD 1991 Food preferences in lambs after exposure to flavors in milk. Appl Anim Behav Sci 32:381-389

27. Weunsch KL 1978 Exposure to onion taste in mother's milk leads to enhanced preference for onion diet among weanling rats. J Gen Psychol 99:163-167

28. Birch LL 1979 Dimensions of preschool children's food preferences. J Nutr Educ 11:77-80

29. Birch LL, Birch D, Marlin DW, Kramer L 1982 Effects of instrumental conditioning on children's food preference. Appetite 3:125-134

30. Capretta PJ, Petersik JT, Stewart DJ 1975 Acceptance of novel flavours is increased after early experience of diverse tastes. Nature 254:689-691

31. Sullivan SA 1992 Infant experience and acceptance of solid foods. PhD dissertation, University of Illinois at Urbana-Champaign 